ARTICLE

DOI: $10.1038 / s 41467-017-02112-z$

\title{
Exceptional increase in the creep life of magnesium rare-earth alloys due to localized bond stiffening
}

Deep Choudhuri (1) 1,2, Srivilliputhur G. Srinivasan', Mark A. Gibson (10) ${ }^{3,4,5}$, Yufeng Zheng ${ }^{6}$, David L. Jaeger ${ }^{7}$, Hamish L. Fraser ${ }^{6}$ \& Rajarshi Banerjee $1,2,7,8$

Several recent papers report spectacular, and unexpected, order of magnitude improvement in creep life of alloys upon adding small amounts of elements like zinc. This microalloying effect raises fundamental questions regarding creep deformation mechanisms. Here, using atomic-scale characterization and first principles calculations, we attribute the $600 \%$ increase in creep life in a prototypical Mg-rare earth (RE)-Zn alloy to multiple mechanisms caused by RE- $Z n$ bonding-stabilization of a large volume fraction of strengthening precipitates on slip planes, increase in vacancy diffusion barrier, reduction in activated crossslip, and enhancement of covalent character and bond strength around $\mathrm{Zn}$ solutes along the c-axis of $\mathrm{Mg}$. We report that increased vacancy diffusion barrier, which correlates with the observed $25 \%$ increase in interplanar bond stiffness, primarily enhances the hightemperature creep life. Thus, we demonstrate that an approach of local, randomized tailoring of bond stiffness via microalloying enhances creep performance of alloys.

\footnotetext{
${ }^{1}$ Department of Materials Science and Engineering, University of North Texas, Denton, TX 76201, USA. ${ }^{2}$ Advanced Materials and Manufacturing Processes Institute, University of North Texas, Denton, TX 76207, USA. ${ }^{3}$ CSIRO Manufacturing, Private Bag 10, Clayton South, Clayton, VIC 3169, Australia. ${ }^{4}$ School of Aerospace, Mechanical and Manufacturing Engineering, RMIT University, Carlton, VIC 3053, Australia. ${ }^{5}$ Department of Materials Engineering, Monash University, Clayton, VIC 3800, Australia. ${ }^{6}$ Center for Accelerated Maturation of Materials, Department of Materials Science and Engineering, The Ohio State University, Columbus, 43210 OH, USA. ${ }^{7}$ Materials Research Facility, University of North Texas, Denton, TX 76201, USA. ${ }^{8}$ School of Materials Science and Engineering, Nanyang Technological University, Singapore, Singapore. Correspondence and requests for materials should be addressed to

D.C. (email: deep.choudhuri@gmail.com) or to S.G.S. (email: srinivasan.srivilliputhur@unt.edu) or to R.B. (email: raj.banerjee@unt.edu)
} 
reep, a time-dependent inelastic deformation occurring at high homologous temperature, limits potential applications of many natural materials and engineering alloys. Traditionally, creep mechanisms in natural materials (e.g., movement of earth's mantle) and engineering alloys were inferred from rigorous experiments and served as critical inputs to creep models ${ }^{1-5}$. Typical mechanisms invoked by conventional creep models are non-conservative vacancy-assisted dislocation climb over obstacles, thermally activated cross-slip, soluteinduced viscous drag on dislocations, jog-assisted dislocation motion, movement through dislocation intersections, and grain boundary sliding $^{6-19}$. Such insights have helped us develop creep- resistant alloys using fine-scale precipitates and dispersion of hard particles to obstruct dislocation motion in the parent matrix ${ }^{15-21}$.

Stress-temperature combinations that cause creep in $\mathrm{Mg}$ alloys during service, e.g., in automotive engine, powertrain applications for example, largely occur via dislocation climb, activated crossslip, and/or grain boundary sliding ${ }^{10-13}$. Consequently, in the case of $\mathrm{Mg}$ alloys, the strategy for precipitation hardening typically selects alloying elements (with lower solubility in $\mathrm{Mg}$, e.g., rare earth elements ${ }^{10,18}$ ) that form precipitates in high number densities on the dominant slip systems ${ }^{20-22}$. Coherent secondary precipitates phases were found to be particularly effective in restraining dislocation motion ${ }^{18}$. Furthermore, depending on processing conditions, e.g., the high-pressure
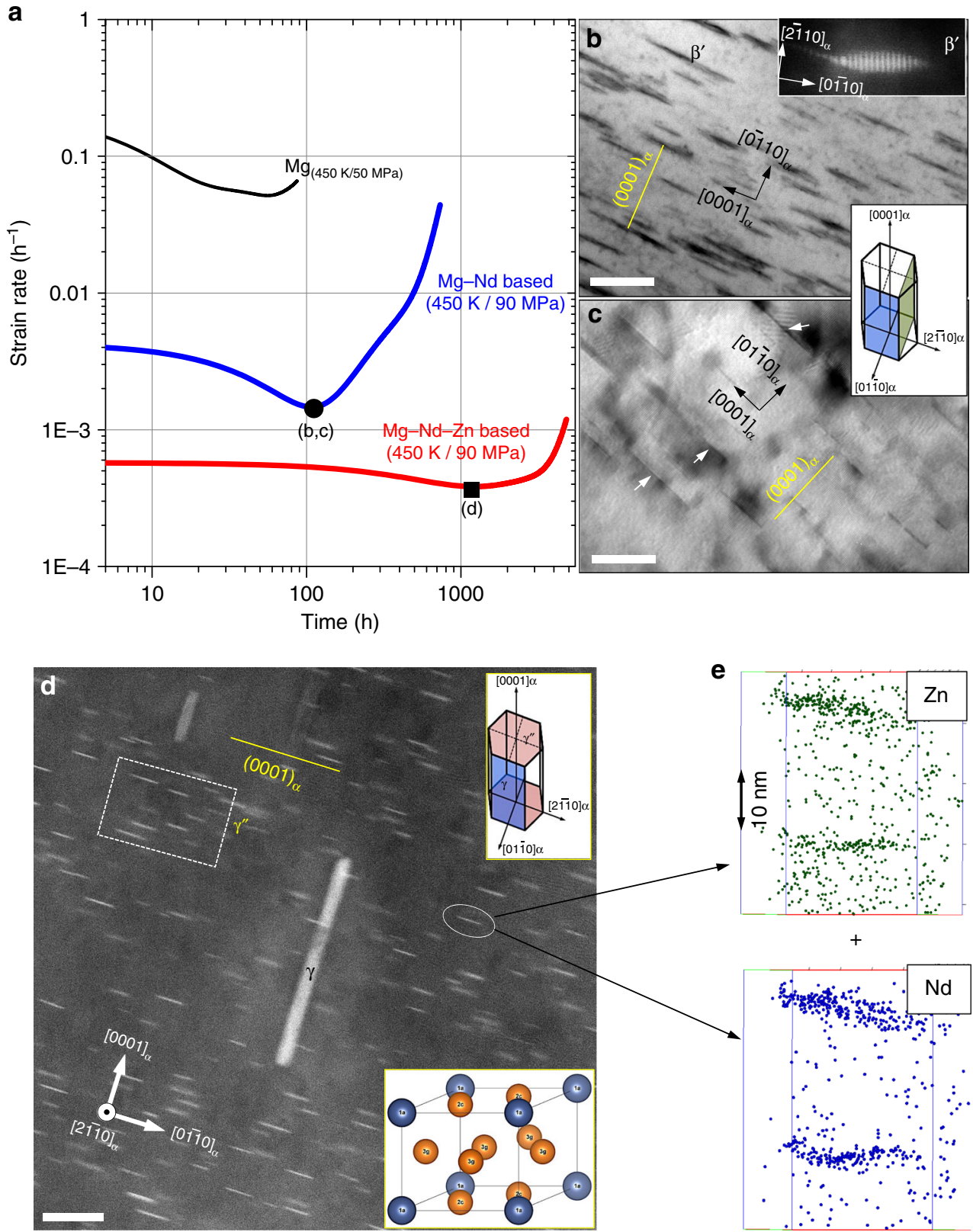

Fig. 1 Creep response and microstructures. a Strain rate vs. time plots show an order of magnitude improvement in the creep life of $\mathrm{Mg}-\mathrm{Nd}-\mathrm{Zn}$ (red) over $\mathrm{Mg}-\mathrm{Nd}$ (blue) and both differ significantly from $\mathrm{Mg}$ (black). Panels b-d are TEM and HAADF-STEM observations for $\mathrm{Mg}-\mathrm{Nd}$ and $\mathrm{Mg}-\mathrm{Nd}-\mathrm{Zn}$ systems taken at points b-d marked in panel a. BFTEMs in panels $\mathbf{b}$ and $\mathbf{c}$ show that $\beta^{\prime}$ precipitates (also inset HAADF-STEM along [1120] $]_{\alpha}$ ) and fine-scale GP zones (arrows), respectively, in Mg-Nd lie on the prismatic planes of hcp-Mg. In case of Mg-Nd-Zn, HAADF-STEM in panel $\mathbf{d}$ shows $\gamma^{\prime \prime}$ and $\gamma$ precipitates lying on both basal and prismatic planes, respectively. e Raw ion maps from atom probe tomography confirms the presence of $\mathrm{Zn}$ in $\gamma^{\prime \prime}$ along with $\mathrm{Nd}$. Scale bars in panels b-d are $100 \mathrm{~nm}, 20 \mathrm{~nm}$, and $20 \mathrm{~nm}$, respectively 
die-casting process, the introduction of large volume fractions of an interdendritic solidification phase/product ${ }^{19}$ can restrict grain boundary sliding. Therefore, in the presence of such microstructural complexities, multiple mechanisms can operate in parallel during creep deformation-as reported by a recent study $^{21}$. This underscores the need to use atomic-scale bonding considerations, in conjunction with above-mentioned conventional approach, to develop next-generation creep-resistant alloys. Our work is a significant step in this direction.

The starting point of this work is our recent exciting discovery that $\mathrm{Zn}$ addition to $\mathrm{Mg}-\mathrm{Nd}-\mathrm{La}$ alloy improved the creep life by $600 \%$, which we correlated to the precipitation of large volume fraction of a new phase on the $\{0002\}_{\alpha}$ basal and $\{1 \overline{1} 00\}_{\alpha} /\{11 \overline{2} 0\}_{\alpha}$ prismatic planes of $h c p-\mathrm{Mg}^{15}$. While the conventional creep models that invoke inhibition of dislocation motion by precipitates in $\mathrm{Mg}-\mathrm{Nd}-\mathrm{La}-\mathrm{Zn}$ alloys predict an increase in creep life, they may not explain the dramatic $600 \%$ increase we observed. Minor $\mathrm{Zn}$ addition to $\mathrm{Mg}$ alloys improves the creep resistance of $\mathrm{Mg}-\mathrm{Gd}$-based alloys via the formation of new $\mathrm{Zn}$-containing precipitate phases ${ }^{18,22,23}$, and segregation of $\mathrm{Zn}$ and $\mathrm{Gd}$ atoms in as-quenched bulk and at the twin boundaries ${ }^{21-23}$. While clearly illustrating the effects of $\mathrm{Zn}$, these studies also fundamentally suggest that $\mathrm{Zn}$ tends to occur near rare earth (RE) atoms, which also determines the precipitation and creep response.

By correlating with atomic-level bonding, the present article sheds light on the root cause of the perplexing association between zinc and $\mathrm{RE}$ atoms and the improvement in creep resistance upon only minor additions ${ }^{20-23}$. We uncover the mechanism(s) contributing to this enhancement in creep lifetime of $\mathrm{Mg}-\mathrm{RE}$ alloys by systematically correlating creep-behavior to microstructures and diffusion processes in high-pressure die-cast $\mathrm{Mg}-0.6 \mathrm{Nd}-0.4 \mathrm{La}$ (at\%) and $\mathrm{Mg}-0.6 \mathrm{Nd}-0.4 \mathrm{La}-0.3 \mathrm{Zn}$ (at\%) alloys (see Supplementary Tables 1 and 2), by coupling atomic-scale microstructural characterization and ab-initio simulations. Past work on Mg-La and Mg-Nd-La alloys has demonstrated that addition of La largely improves alloy castability ${ }^{24}$, but minimally affects the creep behavior. This was attributed to the presence of La primarily inside the large interdendritic solidification phase rather than in $\mathrm{Mg}$ matrix ${ }^{19,24,25}$ (also see Supplementary Fig. 1). Thus, the remainder of the article will refer to alloys with and without $\mathrm{Zn}$ as $\mathrm{Mg}-\mathrm{Nd}$ and $\mathrm{Mg}-\mathrm{Nd}-\mathrm{Zn}$ based. Notwithstanding, we have rigorously evaluated the role of $\mathrm{La}$ on the creep deformation behavior using density functional theory (DFT) calculations.

Our experimental investigations determined creep-response curves of $\mathrm{Mg}, \mathrm{Mg}-\mathrm{Nd}$, and $\mathrm{Mg}-\mathrm{Nd}-\mathrm{Zn}$ systems, and systematically characterized the creep-tested microstructures using transmission electron microscopy (TEM), including aberration corrected high angle annular dark-field scanning TEM (or HAADF-STEM) and atom probe tomography (APT). These experiments were complemented by ab-initio calculations to understand the energetics of vacancy diffusion driven creep, activated climb from the recombination of partials (related to stacking fault energy), and elastic responses. These fundamental material characteristics were further related to microalloyinginduced local lattice-level pockets with covalent character (separated by regions with metallic bonding) inside the $\mathrm{Mg}$ matrix. Such alteration in the local lattice level bonding character was seen to appreciably enhance the local bond stiffness that resembles the modulus mismatch effect in conventional solid solution strengthening mechanism in random alloys and intermetallic phases ${ }^{26-28}$. However, the enhancement of creep tolerance via microalloying-induced $\mathrm{Mg}-\mathrm{Mg}$ bond-stiffening effect presented here significantly differs from that in conventional solid solution strengthening mechanisms in the following manner. While our mechanism continues to operate at high homologous temperature relevant to creep of $\mathrm{Mg}$ alloys, the modulus mismatch effects in conventional solid solution strengthening mechanisms precipitously deteriorate with increasing temperature. Thus, our mechanism provides a viable route to develop new creep-resistant materials.

\section{Results}

We have studied the creep-response and the associated microstructure using multiple techniques. First, we show how microstructures in $\mathrm{Mg}, \mathrm{Mg}-\mathrm{Nd}$, and $\mathrm{Mg}-\mathrm{Nd}-\mathrm{Zn}$ correlate with their creep behavior presented in strain rate time plots in Fig. 1a. We define creep lifetime as the time for the onset of tertiary creep (marked with arrows in Fig. 1a). It is seen that $\mathrm{Nd}$ addition significantly delays the onset of tertiary creep from $\sim 60 \mathrm{~h}$ for the pure $\mathrm{Mg}$ reference material to $460 \mathrm{~h}$ for the base alloy. Remarkably, a further addition of $\mathrm{Zn}$ to $\mathrm{Mg}-\mathrm{Nd}$ alloy extends the onset time to $\sim 3300 \mathrm{~h}$, and reduces the minimum creep strain rate by an order of magnitude (also see Supplementary Fig. 1). Furthermore, we emphasize that $\mathrm{Mg}-\mathrm{Nd}-\mathrm{Zn}$ alloy did not fail even after $\sim 4800 \mathrm{~h}$ of testing. This behavior was attributed originally to the differences in the precipitate distribution in these two alloys ${ }^{20}$. To understand this significant improvement in creep performance by microalloying, we have investigated how the crystallographic orientation of precipitates and their distribution influence the creep behavior by comparing the $\mathrm{Mg}-\mathrm{Nd}$ and $\mathrm{Mg}-\mathrm{Nd}-\mathrm{Zn}$ alloy microstructures at the minimum creep rate. Figures $1 b$ and $c$ show bright-field TEM (BFTEM) images of two types of microstructural entities near the $[11 \overline{2} 0]_{\alpha}$ zone of the $h c p-\mathrm{Mg}$ matrix (hereon referred to as $\alpha$ ). $\mathrm{Mg}-\mathrm{Nd}$ primarily contained coarse ( 20-100 nm long) lenticular $\beta^{\prime}$ (orthorhombic structure ${ }^{18}$, also see the Supplementary Note 2) precipitates (inset in Fig. 1b) and fine-scale ( 10-20 nm long) GP zones (Fig. 1c)—consistent with literature reports ${ }^{18}$. These precipitates formed primarily on the $\{11 \overline{2} 0\}_{\alpha}$ and $\{01 \overline{1} 0\}_{\alpha}$ prismatic planes of the $\alpha-\mathrm{Mg}$ matrix as shown schematically in the middle inset figure. In contrast, precipitates in $\mathrm{Mg}-\mathrm{Nd}-\mathrm{Zn}$ form on both basal $(0002)_{\alpha}$ and prismatic planes of $\alpha-\mathrm{Mg}$. Figure 1d shows a HAADF-STEM image of the precipitates recorded with the electron beam approximately parallel to $[11 \overline{2} 0]_{\alpha}$, and the top-right inset figure shows their habit plane. The highest number density of fine precipitates occurred on the basal planes (see Supplementary Table 3), with number densities an order of magnitude higher than those observed in case of binary $\mathrm{Mg}-\mathrm{Nd}$, whilst a smaller volume fraction of coarser plate-like precipitates are contained in the prismatic planes. The fine and coarse precipitates are $\gamma^{\prime \prime}$ and $\gamma$, respectively ${ }^{18,20}$. The $\gamma^{\prime \prime}$ has a hexagonal structure with space group $\mathrm{P} \overline{6} 2 \mathrm{~m}^{18,20}$ and $\gamma$ has a cubic structure with space group $\mathrm{Fm} \overline{3} \mathrm{~m}$, like $\beta_{1}$ phase in the $\mathrm{Mg}-\mathrm{Nd}$ alloy (see Supplementary Note 2$)^{18,20}$. APT analysis of these $\gamma^{\prime \prime}$ precipitates clearly revealed an enrichment of $\mathrm{Nd}$ and $\mathrm{Zn}$ within them (shown in Fig. 1e). Furthermore, at the minimum creep rate, the number density of $\gamma^{\prime \prime}$ in $\mathrm{Mg}-\mathrm{Nd}-\mathrm{Zn}$ is one order of magnitude larger than $\beta_{1}$ precipitates in $\mathrm{Mg}-\mathrm{Nd}^{20}$. Therefore, from this comparative microstructural analysis and creep testing results, we infer that $\gamma^{\prime \prime}$ precipitates on the basal planes must play a crucial role in enhancing the creep strength of $\mathrm{Mg}-\mathrm{Nd}-\mathrm{Zn}$. A description of precipitation sequence in $\mathrm{Mg}$ alloys is included in the Supplementary Note 2.

The structure and stability of the critical strengthening precipitate $\gamma^{\prime \prime}$ has been investigated here in detail, with a focus on the most probable site/elemental occupancies in this ternary intermetallic compound consisting of $\mathrm{Mg}$ as the primary element with varying lattice site occupancies of $\mathrm{Zn}$ and $\mathrm{Nd}$. The $\gamma^{\prime \prime}$ differs from the simpler binary phases typically observed in the $\mathrm{Mg}-\mathrm{Nd}$ system, and reported in the literature. These differences have been explained in detail, based on our experimentally observed and 

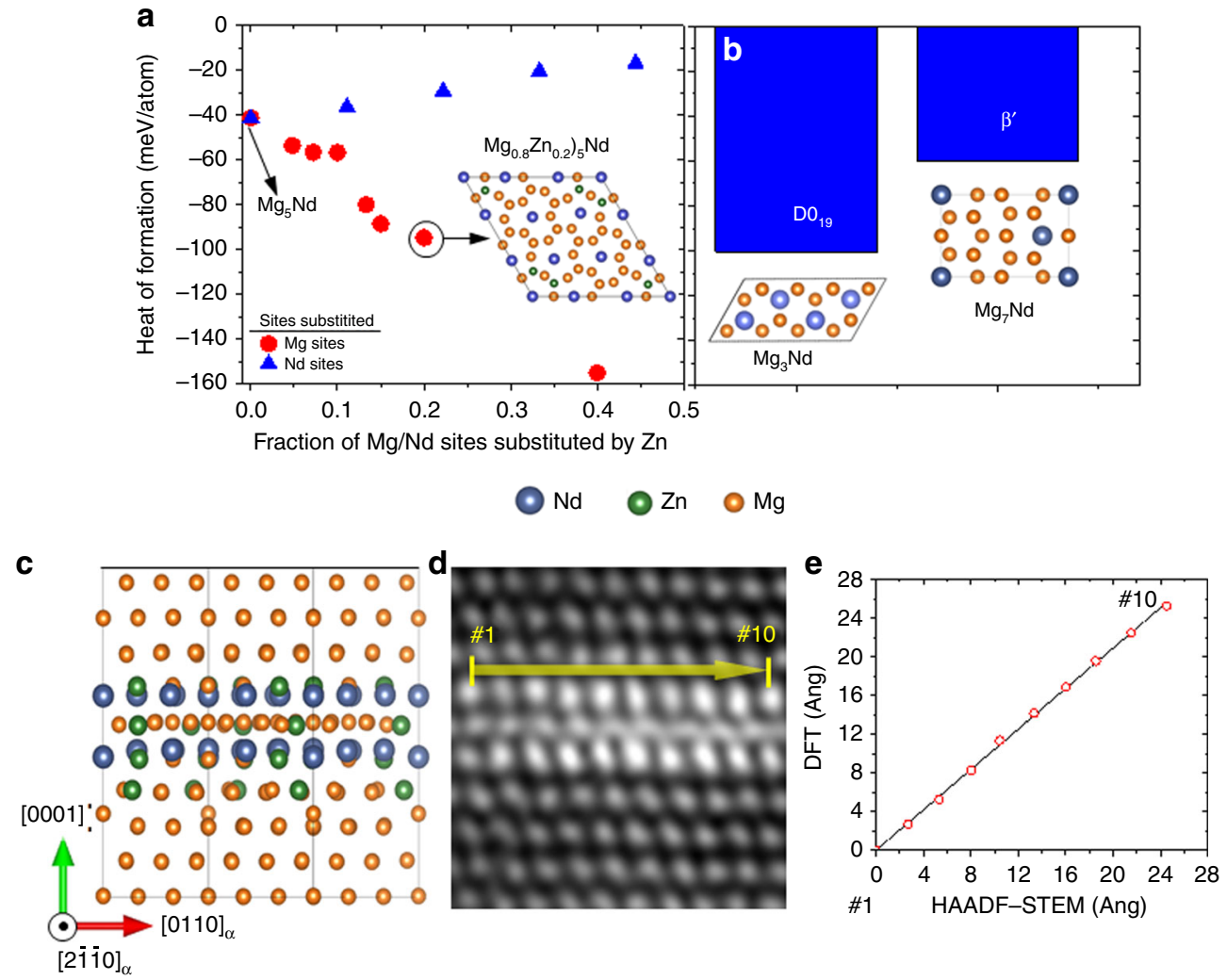

Fig. $2 \gamma^{\prime \prime}$ structure after Zn substitution. a Heat of formation of $\gamma^{\prime \prime}$ is plotted as a function of the fraction of Mg and Nd sites substituted by Zn. $\mathbf{b}$ Heats of formation for D019 and $\beta^{\prime}$. Panels c-e show experimental observation and DFT calculations agree well: c DFT-derived structure of $\left(\mathrm{Mg}_{0.8} \mathrm{Zn}_{0.2}\right)_{5} \mathrm{Nd} \gamma^{\prime \prime}$ supercell sandwiched in a Mg matrix, $\mathbf{d}$ atomic resolution HAADF-STEM image of $\gamma^{\prime \prime}$, and e plot comparing interatomic distances obtained from DFT calculations and measurements performed in the HAADF-STEM image

simulated electron diffraction patterns, based on ab-initio calculations, and shown in Supplementary Fig. $2 \mathrm{a}-\mathrm{d}$. The basic unit cell of $\gamma^{\prime \prime}$ with Wyckoff positions $\mathrm{Nd} 11 a, \operatorname{Mg} 13 g$, and Mg2 $2 c$ (stoichiometry $\mathrm{Mg}_{5} \mathrm{Nd}$ and space group $\mathrm{P} \overline{6} 2 \mathrm{~m}$ ) is shown in the bottom inset of Fig $1 \mathrm{~d}^{18}$. Subsequently, $\gamma^{\prime \prime}$ supercells with differing site occupancies were constructed by substituting either $\mathrm{Mg}$ or $\mathrm{Nd}$ sites with $\mathrm{Zn}$ atoms in varying fractions, whilst maintaining the symmetry.

The stability of $\gamma^{\prime \prime}, \mathrm{D0}_{19}$ (stoichiometry $\mathrm{Mg}_{3} \mathrm{Nd}$ ), and $\beta^{\prime}$ (stoichiometry $\mathrm{Mg}_{7} \mathrm{Nd}$ ) phases were evaluated at $0 \mathrm{~K}$ (Fig. 2a), by calculating their heats of formation $\left(H_{f}\right)$. These results, in conjunction with APT and HAADF-STEM results, were used to examine the role and stability of precipitate matrix interfaces. The $\mathrm{D0}_{19}$ structure is believed to be present in $\mathrm{Mg}-\mathrm{Nd}$ as GP zones ${ }^{18,29}$. We found that energetics favor $\mathrm{Zn}$ substitution at $\mathrm{Mg}$ sites over $\mathrm{Nd}$ sites. Interestingly, one of the predicted $\gamma^{\prime \prime}$ compositions (Mg-16Nd-16Zn (at.\%) or $\left(\mathrm{Mg}_{0.8} \mathrm{Zn}_{0.2}\right)_{5} \mathrm{Nd}$ and marked in the inset of Fig. 2a) is comparable to the $\gamma^{\prime \prime}$ composition determined from APT: $\mathrm{Mg}-(13-14$ at.\%)Nd-(9-13at.\%)Zn. The APT compositions were determined by employing a cluster analysis algorithm to several APT data sets ${ }^{30,31}$. Additionally, $\gamma^{\prime \prime}-\left(\mathrm{Mg}_{0.8} \mathrm{Zn}_{0.2}\right)_{5} \mathrm{Nd}$, with $H_{f}$ of $-95 \mathrm{meV} /$ atom and hereon referred to as $\gamma^{\prime \prime}$, has an energetic stability similar to $\mathrm{D} 0_{19}$ $(-100 \mathrm{meV} /$ atom $)$. However, it is more stable than $\beta^{\prime}(-60 \mathrm{meV} /$ atom). From these values, we can infer that the formation of $\mathrm{D0}_{19}$ and $\gamma^{\prime \prime}$ phases, in $\mathrm{Mg}-\mathrm{Nd}$ and $\mathrm{Mg}-\mathrm{Nd}-\mathrm{Zn}$ respectively, are equally favored. Yet, phases that are stable at $T=0 \mathrm{~K}$ may not be so at higher temperatures, and may even be absent in the microstructure. For example, the bulk $\mathrm{D}_{19}$ structure, despite its large $H_{f}$ value, does not exist as a monolithic precipitate within the $h c p-\mathrm{Mg}$ matrix ${ }^{32,33}$. Instead, GP zones are reported to exist as very fine nano-scale ordered arrangements within the $h c p-\mathrm{Mg}$ matrix and not with the postulated $\mathrm{D0}_{19}$ structure $^{33}$. This indicates that the energy of the precipitate-matrix interface is likely to play a significant role in stabilizing the precipitate.

A detailed study of $\gamma^{\prime \prime} / \mathrm{Mg}$ interface is beyond the scope of this work. However, our TEM studies of $\mathrm{Mg}-\mathrm{Nd}-\mathrm{Zn}$ microstructure suggests that a stable $\gamma^{\prime \prime} / \mathrm{Mg}$ interface exists, unlike unstable $\mathrm{D} 0_{19}$ in $\mathrm{Mg}-\mathrm{Nd}$. The structure of $\gamma^{\prime \prime}-\left(\mathrm{Mg}_{0.8} \mathrm{Zn}_{0.2}\right)_{5} \mathrm{Nd}$ was further confirmed by comparing our DFT calculations with atomically resolved aberration corrected HAADF-STEM microscopy results presented in Fig. 2c and d, respectively. The HAADF-STEM images, shown in Fig. 2d, and in Supplementary Fig. 3, clearly reveal higher intensity atomic columns, corresponding to heavier elements $^{34,35}$, at the same locations where the $\mathrm{Nd}$ and $\mathrm{Zn}$ atoms occupy the $\gamma^{\prime \prime}$ structure in the DFT simulations (Fig. 2c). Additionally, the distances between the atomic columns along the row exhibiting the brightest intensity, marked as \#1 to \#10, are in excellent agreement with those obtained from the DFT-simulated structure, as shown in Fig. 2e. Such a coupled TEM-DFT approach was essential because $2 \mathrm{D}$ projections associated with TEM, irrespective of resolution, do not reliably allow identification of $\mathrm{Zn}$ site in the $\gamma^{\prime \prime}$ lattice. The large $H_{f}$ of $\gamma^{\prime \prime}$ when $\mathrm{Zn}$ substitutes in $\mathrm{Mg}-\mathrm{Nd}$, and its high number density, and widespread presence and stability (does not dissolve; see Supplementary Fig. 4), after prolonged creep testing at elevated temperature, leads us to hypothesize that the $\gamma^{\prime \prime}$ precipitates are likely to be the critical barrier to dislocation glide during creep at higher stresses. We will also emphasize that the precipitates in both alloys will coarsen with prolonged creep (see Supplementary 


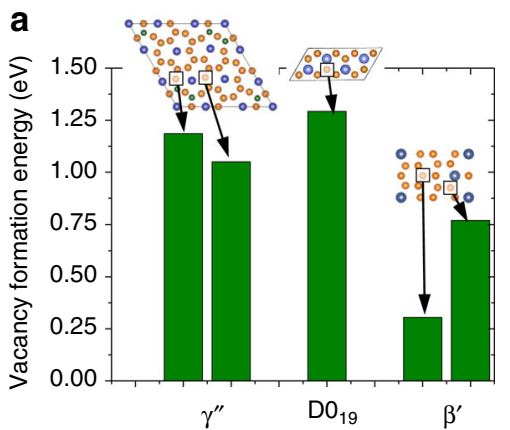

b

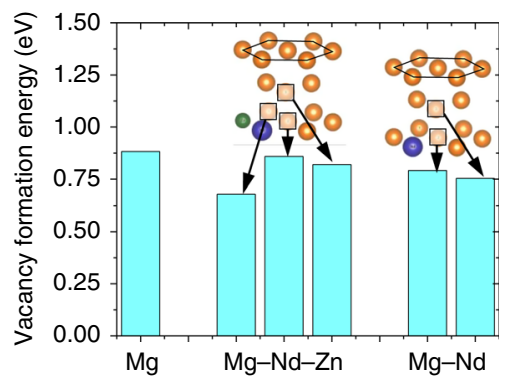

Vacancy

Only Nd $-\triangle-$ Pure Mg

C

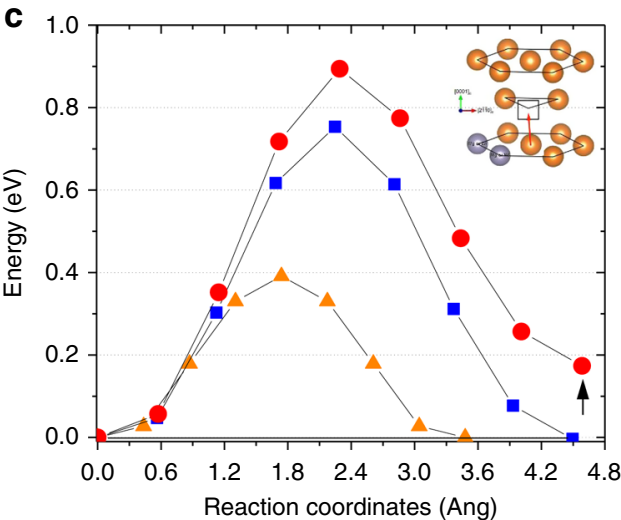

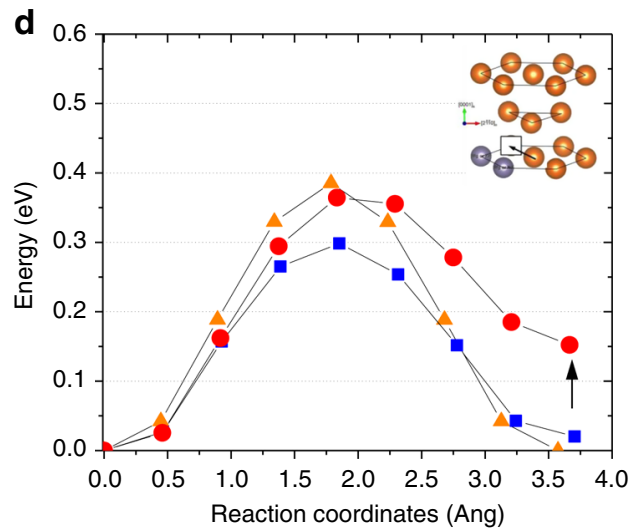

Fig. 3 Formation and migration energies of vacancy at $\mathrm{Mg}$ sites. Heat of vacancy formation at $\mathrm{Mg}$ sites in: a $\gamma^{\prime \prime}, \mathrm{DO}_{19}$, and $\beta^{\prime}$ structures; $\mathbf{b}$ hcp-Mg lattice with no solutes, $\mathrm{Nd}$ and $\mathrm{Zn}$ solutes, and only $\mathrm{Nd}$ solute. Energies were calculated for vacancies at different nearest neighbor distances to Nd and/or Zn. Energy vs. reaction coordinates plots showing transition state calculations for out-of-plane (c) and in-plane (d) vacancy migration. The insets in $\mathbf{c}$ and $\mathbf{d}$ schematically show the migration paths in $h c p-M g$. Addition of $\mathrm{Zn}$ retards $\mathrm{Mg}$ vacancy migration by increasing the peak-barrier and final saddle point energies (marked with arrow in c-d)

Fig. 4 and ref. ${ }^{36}$ ), and that will inevitably reduce creep lifetime of both systems.

Presently, in order to explain an order of magnitude reduction in the minimum creep rates, we further used precipitate number densities in $\mathrm{Mg}-\mathrm{Nd}$ and $\mathrm{Mg}-\mathrm{Nd}-\mathrm{Zn}$, measured from BFTEM images, as inputs to different strengthening models to estimate creep enhancements in the $\mathrm{Mg}-\mathrm{Nd}-\mathrm{Zn}$ system (see Supplementary Note 3). Furthermore, our DFT calculations revealed that elastic moduli of $\gamma^{\prime \prime}$ are comparable to pure Mg (see Supplementary Table 4 and Supplementary Note 3) and hence do not significantly strengthen $\mathrm{Mg}$ matrix by the modulus effect ${ }^{14,18,37,38}$. Classical precipitation strengthening models ${ }^{14,37,38}$ predict only a 3 -fold increase in the critical resolved shear stress (CRSS) for the $\gamma^{\prime \prime}$ fractions estimated in $\mathrm{Mg}-\mathrm{Zn}-\mathrm{Nd}$ (see Supplementary Table 5). However, any interpretation solely based on microstructure fails to explain the observed improvement in the creep lifetime in $\mathrm{Mg}-\mathrm{Nd}-\mathrm{Zn}$. Reasonable explanations must also consider vacancy interaction with precipitates and solutes, and acceleration of dislocation climb over impeding precipitates, driven by enhanced vacancy diffusion at high homologous temperature, and activated crossslip of screw dislocations ${ }^{10-13}$.

We now determine vacancy energetics using first-principle calculations to understand their role in the superior creep lifetime of our $\mathrm{Mg}-\mathrm{Nd}-\mathrm{Zn}$ alloy. The formation energies of $\mathrm{Mg}$ vacancies in $\gamma^{\prime \prime}, \mathrm{D} 0_{19}$, and $\beta^{\prime}$ precipitates are compared with that in the hcp-Mg lattice with different solute environments (Fig. 3b). Figure $3 \mathrm{a}$ and $\mathrm{b}$ show formation energy $\left(E_{f}\right)$ of $\mathrm{Mg}$ vacancy sites that are at different nearest neighbor (NN) distances from
$\mathrm{Nd}$, and $\mathrm{Nd}$ and $\mathrm{Zn}$. They reveal that vacancies form more easily in pure $\mathrm{Mg}$ and without solutes $\left(E_{f}=0.68-0.88 \mathrm{eV}\right)$ than in $\gamma^{\prime \prime} \quad\left(E_{f}=1.19\right.$ and $\left.1.05 \mathrm{eV}\right)$ and $\mathrm{D}_{19} \quad\left(E_{f}=1.29 \mathrm{eV}\right)$ precipitates. Surprisingly, vacancy formation energy values of $E_{f}=0.30-0.77 \mathrm{eV}$ in the coarser $\beta^{\prime}$ precipitates are comparable or less than those in the Mg lattice. Thus, vacancies will easily form in $\mathrm{Mg}-\mathrm{Nd}$, both in $\mathrm{Mg}$ matrix and in $\beta^{\prime}$-in potentially higher concentrations. They will undoubtedly be an important facilitator of dislocation climb during creep. In contrast, the larger vacancy formation energy in $\gamma^{\prime \prime}$ precipitates, present in larger densities in $\mathrm{Mg}-\mathrm{Nd}-\mathrm{Zn}$ than either $\mathrm{D}_{19}$ or $\beta^{\prime}$ in $\mathrm{Mg}-\mathrm{Nd}$, suggests that vacancy formation in $\gamma^{\prime \prime}$ is less likely. Instead vacancies will form predominantly within the $\mathrm{Mg}$ solid solution, and that vacancy migration within the $\mathrm{Mg}-\mathrm{Nd}-\mathrm{Zn}$ alloy matrix may likely play a key role in creep.

In $h c p$ metals, there are two primary paths for vacancy diffusion-out-of-plane (OOP) between two (0002) $)_{\alpha}$ planes and in-plane (IP) within a (0002) $\alpha$ plane $\mathrm{e}^{39}$. Thus, we next calculated migration energies for these paths in $\mathrm{Mg}, \mathrm{Mg}-\mathrm{Nd}$, and $\mathrm{Mg}-\mathrm{Nd}-\mathrm{Zn}$ matrices via the nudged-elastic-band (NEB) $\operatorname{method}^{40}$, using 96 atom supercells for numerical accuracy (see Supplementary Fig. 5 for the vacancy diffusion paths). The OOP and IP migration barriers for reference pure $\mathrm{Mg}$ are 0.38 and $0.39 \mathrm{eV}$, respectively, and in agreement with literature ${ }^{41}$. Figure $3 c$ and $d$ plot minimum energy path (MEP) for OOP and IP vacancy diffusion for different solute environments (also see extended Fig. e4). The addition of a $\mathrm{Zn}$ atom as the first neighbor to an $\mathrm{Nd}$ atom substituted within the $\mathrm{Mg}$ lattice increased the OOP migration energy $\sim 125 \%$ compared to the 


\section{a}
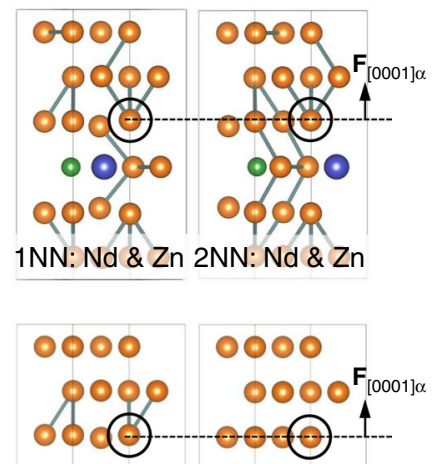

[0001] $]_{\alpha}$ Only Nd Pure Mg<smiles>CCCC</smiles>

b

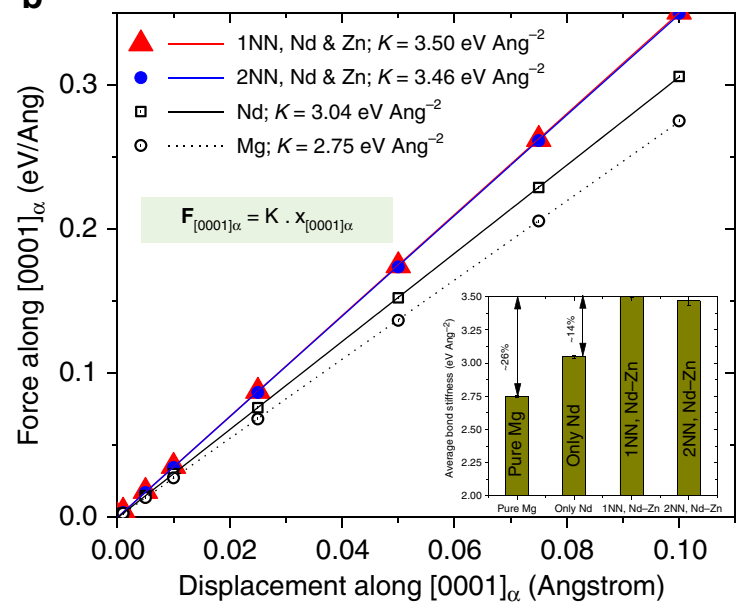

- $\mathrm{Nd} \odot \mathrm{Zn}$ OMg
C

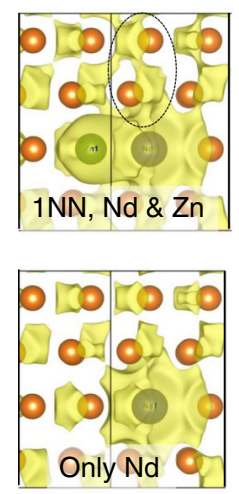

d

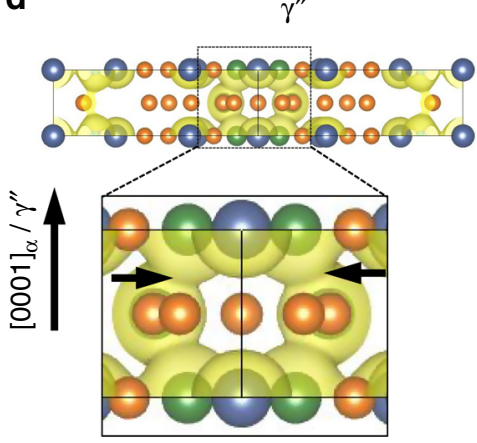

e

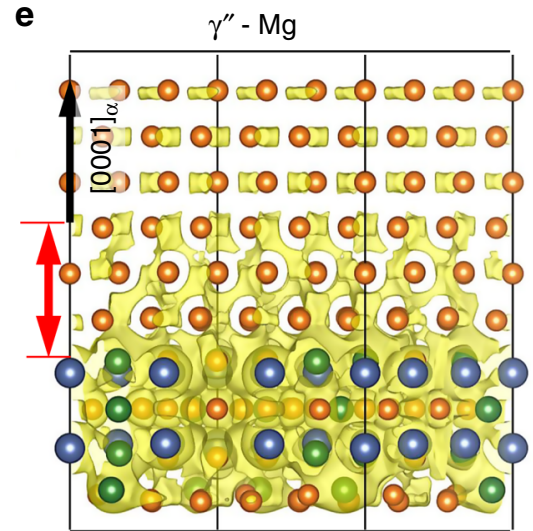

Fig. 4 Bonding character from DFT calculations. a Mg lattice supercells showing Nd and Zn solutes as 1st and 2nd nearest neighbors (NN), only Nd solute, and pure $\mathrm{Mg}$. The encircled $\mathrm{Mg}$ atom was displaced along the [0001] $]_{\alpha}$ to calculate the restoring force. $\mathbf{b}$ Plot of DFT-calculated force as function of displacement along [0001] $]_{\alpha}$. The inset histogram shows the calculated bond stiffness increases with $\mathrm{Zn}$ addition. Charge isosurface using $\Delta \rho=0.015$ e $\AA^{-3}$ in panels c-e shows the valence electron delocalization along [0001] $]_{\alpha}$ in solid solution, bulk $\gamma^{\prime \prime}$, and $\gamma^{\prime \prime}-\mathrm{Mg}$ supercells in $\mathrm{Mg}-\mathrm{Nd}-\mathrm{Zn}$ system

pure $\mathrm{Mg}$ (Fig. 3c), and $\sim 18 \%$ with respect to only $\mathrm{Nd}$ substitution. The $\mathrm{Zn}$ addition, on the other hand, did not appreciably change IP vacancy migration barrier for $\mathrm{Mg}$ diffusion (Fig. 3d). From Fig. $3 c$ and $d$, we observe that one of the saddle points for $\mathrm{Mg}-\mathrm{Nd}-\mathrm{Zn}$ (marked with arrow) has a higher energy than the initial configuration. This causes the OOP and IP vacancy migration in the presence of both $\mathrm{Zn}$ and $\mathrm{Nd}$ to create an energetically unfavorable configuration. Furthermore, as described above and summarized in Fig. $3 c$ and $d$, the OOP and IP vacancy migration barrier energies follow the trend: $E_{\mathrm{Mg}-\mathrm{Nd}-\mathrm{Zn}}^{\mathrm{OOP}}>E_{\mathrm{Mg}-\mathrm{Nd}}^{\mathrm{OOP}}>E_{\mathrm{Mg}}^{\mathrm{OOP}}$, and $E_{\mathrm{Mg}-\mathrm{Nd}-\mathrm{Zn}}^{\mathrm{ip}} \approx E_{\mathrm{Mg}}^{\mathrm{i}}>E_{\mathrm{Mg}-\mathrm{Nd}}^{\mathrm{ip}}$. Interestingly, this trend in OOP energy barriers correlates well with the increase in creep strength and failure-time in Fig. 1a. $\mathrm{NEB}$ calculations involving $\mathrm{Mg}-\mathrm{La}$ and $\mathrm{Mg}-\mathrm{La}-\mathrm{Zn}$ also indicated similar trends (Supplementary Fig. 6 and Supplementary Note 5). Thus, we can infer that OOP vacancy diffusion, necessary for dislocation climb, appears to be the rate-determining step of creep in $\mathrm{Mg}-\mathrm{Nd}-\mathrm{Zn}$ alloys.

The trend in vacancy migration barriers was correlated to $\langle 0001\rangle_{\alpha}$ and $\langle 11 \overline{2} 0\rangle_{\alpha}$, the $\mathrm{Mg}-\mathrm{Mg}$ bond stiffness $(K)$ by varying the solute environments (Fig. 4a). The bond stiffness was determined systematically by displacing a $\mathrm{Mg}$ atom along $[0001]_{\alpha}$ and determining the corresponding restoring Hellman-Feynman forces (plotted in Fig. 4b). The excellent straight-line fits in Fig. 4b indicated that the displacements were within harmonic limits and allowed us to calculate $K$ for each solute environment from the linear slopes. The results show that the presence of $\mathrm{Zn}$ and $\mathrm{Nd}$ (as 1 st or 2 nd $\mathrm{NN}$ ) increased [0001] $]_{\alpha}$ stiffness by $26 \%$ and $14 \%$ compared to $\mathrm{Mg}$ and $\mathrm{Mg}-\mathrm{Nd}$ systems. The bond stiffness along the $a$-axis $\left(\langle 11 \overline{2} 0\rangle_{\alpha}\right)$ did not differ significantly between pure $\mathrm{Mg}$ and the Zn-containing supercells (Supplementary Fig. 7). Importantly, bond stiffness trend parallels the OOP migration barriers: $K_{\mathrm{Mg}-\mathrm{Nd}-\mathrm{Zn}}^{1 \mathrm{NN}} \approx K_{\mathrm{Mg}-\mathrm{Nd}-\mathrm{Zn}}^{2 \mathrm{NN}}>K_{\mathrm{Mg}-\mathrm{Nd}}>K_{\mathrm{Mg}}$.

The higher bond stiffness along [0001 $]_{\alpha}$ in $\mathrm{Mg}-\mathrm{Nd}-\mathrm{Zn}$, and its correlation with OOP diffusion barrier, was further analyzed using the electronic charge distribution around the solute atoms in the $\mathrm{Mg}$ lattice (Fig. 4c). The presence of $\mathrm{Zn}$ near an $\mathrm{Nd}$ atom localizes anisotropically the excess electron density along $[0001]_{\alpha}$ as shown by dotted ellipses around $\mathrm{Zn}$ and $\mathrm{Nd}$ (Fig. 4e). Such valence electron density localization was also verified in larger 500 supercells where $\mathrm{Nd}$ and $\mathrm{Zn}$ concentrations are well within their experimentally measured values. This localization signifies an increased covalent bond character in $\mathrm{Mg}-\mathrm{Nd}-\mathrm{Zn}^{27,28}$, which correlates with the increased stiffness along $[0001]_{\alpha}$. Such Zn-addition-induced covalent character also exists in other cases. Electron charge localization between the $(0001)_{\gamma^{\prime \prime}}$ binds the two planes (shown by arrows in Fig. 4d) and stabilizes $\gamma^{\prime \prime}$ as evidenced by its more negative $H_{f}$ (Fig. 2a). In contrast, such interplanar 
localization is absent in $\gamma^{\prime \prime}$ precipitates without $\mathrm{Zn}$ substitution and when $\mathrm{Zn}$ substitutes for Nd atoms (Supplementary Fig. 8a), which also explains the higher formation energies of these structures (Fig. 2a).

Electronic charge distribution around the $\gamma^{\prime \prime} / \mathrm{Mg}$ interfacial regions was also studied (Fig. $4 \mathrm{~d}$ ). The calculations showed that electronic charge were localized at three $(0002)_{\alpha}$ planes of the $\mathrm{Mg}$ lattice in $\gamma^{\prime \prime} / \mathrm{Mg}$ interface, while charge localization persisted to the nearest $(0002)_{\alpha}$ plane of the $\mathrm{Mg}-\mathrm{Nd}$-based structures (Supplementary Fig. 8b). This observation is significant because the $\gamma^{\prime \prime}$ precipitates are better bonded to its surrounding parent $\mathrm{Mg}$ lattice than $\beta^{\prime}$ in $\mathrm{Mg}-\mathrm{Nd}$, and the enhanced covalent bonding of the $\gamma$ "/Mg interfacial regions can likely inhibit diffusing vacancies during creep. Additionally, our recent study of precipitate-matrix interfaces in a Mg-RE alloy indicated that lower interfacial energy correlates with higher interfacial valence charge density (also see Supplementary Note 3$)^{42}$. Taken together, the stiffer bonds near the solute species and $\gamma^{\prime \prime} / \mathrm{Mg}$ interfacial regions will form a distribution of covalently bonded pockets within the matrix of $\mathrm{Mg}-\mathrm{Nd}-\mathrm{Zn}$. These stiff pockets will raise the vacancy migration barrier in $\mathrm{Mg}-\mathrm{Nd}-\mathrm{Zn}$ by an order of magnitude over $\mathrm{Mg}-\mathrm{Nd}$, and correspondingly reduces the dislocation-climb-dominated creep rates by the same factor (Supplementary Note 4 and Supplementary Tables 6 and 7).

Finally, to evaluate the role of activated cross-slip during creep, basal stacking fault energy (SFE) of $1 / 3\langle 1 \overline{1} 00\rangle_{\alpha}$ partial dislocations in pure $\mathrm{Mg}, \mathrm{Mg}-\mathrm{Nd}$, and $\mathrm{Mg}-\mathrm{Nd}-\mathrm{Zn}$ alloys were computed from their generalized stacking fault energy (GSFE) curves (see Supplementary Methods Section). In Fig. 5a, the SFE for the intrinsic I2 stacking faults in $h c p$ metals ${ }^{43,44}$ corresponds to the first minima of the GSFE curves, and they vary as $\mathrm{I} 2_{\mathrm{Mg}-\mathrm{Nd}-\mathrm{Zn}}<$ $\mathrm{I} 2{ }_{\mathrm{Mg}-\mathrm{Nd}}<\mathrm{I} 2_{\text {pure } \mathrm{Mg}}$. Note that $\mathrm{I} 2_{\mathrm{Mg}-\mathrm{Zn}} \approx \mathrm{I} 2_{\text {pure } \mathrm{Mg}}$ (see Supplementary Fig. 9). For partials (with screw character ${ }^{14}$ ) to cross-slip to a different plane, they first need to recombine into a perfect lattice dislocation, and the work done to drive that process is equivalent to the dislocation dissociation energy of the lattice dislocation. The SFE was related to the dissociation energy (see equation 2 in the Supplementary Methods Section). The calculated values are plotted as bars in Fig. 5b, which also compares the dissociation energies of pure $\mathrm{Mg}, \mathrm{Mg}-\mathrm{Nd}$, and $\mathrm{Mg}-\mathrm{Nd}-\mathrm{Zn}$ alloys with their OOP and IP migration barriers (Fig. 3c, d). We note that the addition of $\mathrm{Zn}$ to $\mathrm{Mg}-\mathrm{Nd}$ increases the dissociation energy, which means that $\mathrm{Zn}$ is more effective in hindering activated cross-slip in $\mathrm{Mg}-\mathrm{Nd}-\mathrm{Zn}$ alloys. Furthermore, the calculated higher OOP migration energy (see Fig. 5b) demonstrates that OOP dislocation climb faces a greater energy penalty than IP vacancy diffusion and activated cross-slip. Similar results were also obtained for $\mathrm{Mg}-\mathrm{La}$ and $\mathrm{Mg}-\mathrm{La}-\mathrm{Zn}$ (Supplementary Note 5 and Supplementary Fig. 9).

\section{Discussion}

This letter has identified several key mechanisms responsible for the dramatic improvement of creep lifetime of $\mathrm{Mg}-\mathrm{Nd}-\mathrm{Zn}$. First, the presence of Zn-stabilized $\gamma^{\prime \prime}$ on basal planes and the cubic $\gamma$ precipitates on the prismatic planes (Fig. 1d) restricts dislocation movement on the dominant slip systems of $\mathrm{Mg}-\mathrm{Nd}-\mathrm{Zn}$ compared to arresting only the prismatic slip in $\mathrm{Mg}-\mathrm{Nd}$. This physical encompassing of the $h c p-\mathrm{Mg}$ lattice via precipitates has been postulated earlier from "honeycomb" structures seen in $\mathrm{Mg}-\mathrm{Nd}-\mathrm{Y}$ alloys,${ }^{18}$. However, with $\mathrm{Zn}$ addition, we have been able to attain a very high number density of $\gamma^{\prime \prime}$ and precipitation on both basal and prismatic planes. Regardless, conventional creep models show that the $\gamma^{\prime \prime}$ precipitate orientation and their high number density only enhances the CRSS of Mg-Nd-Zn by a factor of three. Second, we show that the presence of both $\mathrm{Zn}$ and
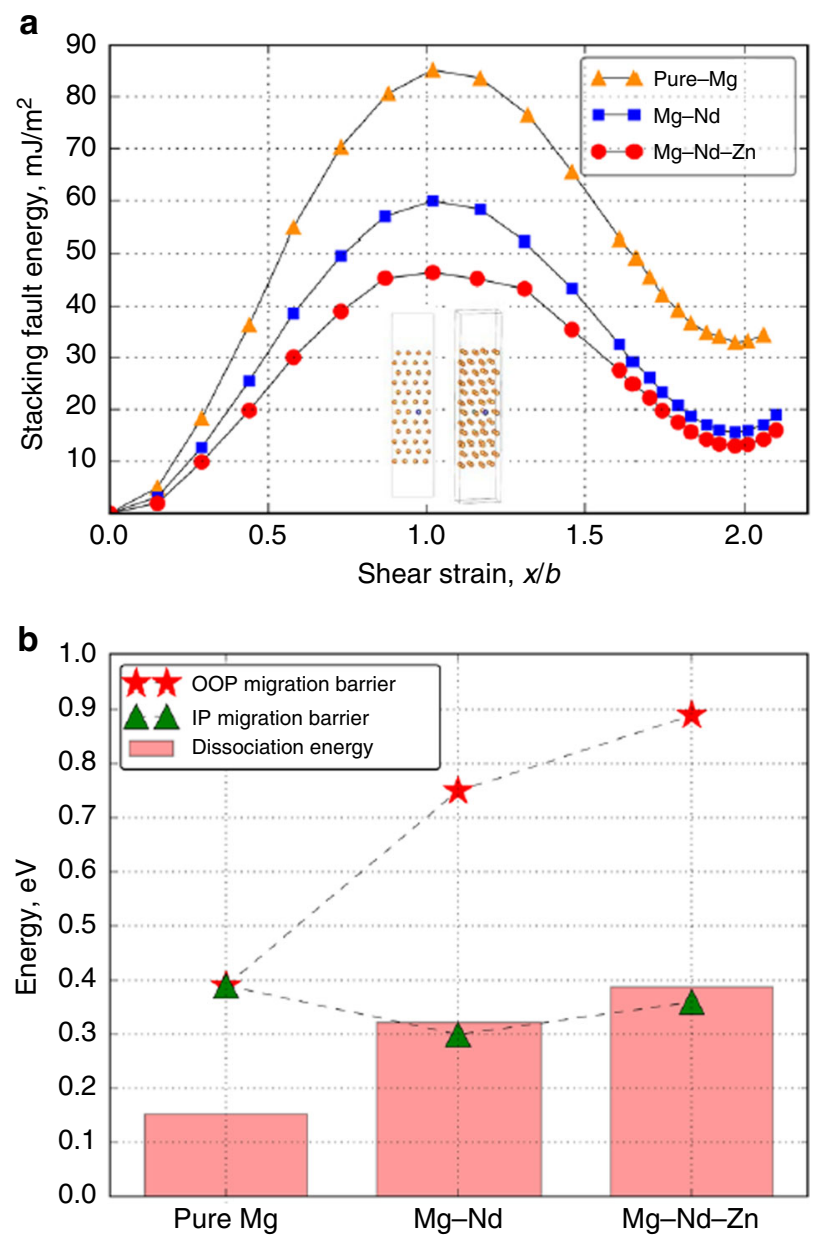

Fig. 5 Generalized stacking fault (GSF) and dislocation dissociation energies. a Plot depicting the variation of fault energy with planar displacement along $\langle 11 \overline{2} \mathrm{O}\rangle_{\alpha}$ in pure $\mathrm{Mg}, \mathrm{Mg}-\mathrm{Nd}$, and $\mathrm{Mg}-\mathrm{Nd}-\mathrm{Zn}$. Bottom inset figures show two views of the orthogonal cell used in the calculations. Stacking fault energy corresponds to the first minima of the GSF energy curves. Addition of $\mathrm{Zn}$ to $\mathrm{Mg}-\mathrm{Nd}$ further reduces SFE by $\sim 17 \%$. b Histogram comparing the energy required to dissociate a perfect $(1 / 2)\langle 11 \overline{2} 0\rangle_{\alpha}$ dislocation into two $(1 / 3)\langle 1 \overline{1} 00\rangle_{\alpha}$ partials for pure $\mathrm{Mg}, \mathrm{Mg}-\mathrm{Nd}$, and $\mathrm{Mg}-\mathrm{Nd}-\mathrm{Zn}$ alloys. Adding $\mathrm{Zn}$ to $\mathrm{Mg}-\mathrm{Nd}$ increases the dissociation energy by $\sim 20 \%$. Out-of-plane vacancy migration energies, also indicated in the same plot, are also significantly larger than the dissociation energies

$\mathrm{Nd}$ strengthens the interplanar bonding by imparting covalent bond character within the $\mathrm{Mg}$ matrix and at the $\gamma^{\prime \prime} / \mathrm{Mg}$ interfaces. A distribution of such local covalently bonded regions inside the $\mathrm{Mg}$ matrix of $\mathrm{Mg}-\mathrm{Nd}-\mathrm{Zn}$ alloy increased the OOP vacancy migration energy barrier by an order of magnitude compared to such a barrier in $\mathrm{Mg}-\mathrm{Nd}$. Third, the increased vacancy migration barrier correlated with an order of magnitude reduction in creep strain-rate of $\mathrm{Mg}-\mathrm{Nd}-\mathrm{Zn}$. Therefore, the alteration of electronic structure via alloying with $\mathrm{Zn}$ is a potential approach for alloy strengthening because we are fundamentally imparting covalent character to increase the bond strength. Finally, Zn addition also likely hinders the activated cross-slip by reducing the stacking fault energies. Thus, we note that the creep response of the $\mathrm{Mg}-\mathrm{Nd}-\mathrm{Zn}$ alloy is enhanced by the interaction of multiple factors related to chemical bonding along the $[0001]_{\alpha}$ crystallographic axis of hcp-Mg. However, it needs to be determined whether these mechanisms affect the creep strength in either linear or non-linear combinations. 
In conclusion, using $\mathrm{Mg}-\mathrm{Nd}$ and $\mathrm{Mg}-\mathrm{Nd}-\mathrm{Zn}$ model alloys, we have discovered that engineering stiffer directional bonds by using appropriate microalloying additions can dramatically improve their high temperature creep response. Our findings have bearing not only on the design of ultra-lightweight creep resistant $\mathrm{Mg}$ alloys, but may also guide the future development of other alloy systems.

\section{Methods}

Alloys of composition (in at\%) $\mathrm{Mg}-0.6 \mathrm{Nd}-0.4 \mathrm{La}$ and $\mathrm{Mg}-0.6 \mathrm{Nd}-0.4 \mathrm{La}-0.3 \mathrm{Zn}$ were creep tested at $450 \mathrm{~K}$ with a constant tensile stress of $90 \mathrm{MPa}$. Characterization of the deformed microstructure was performed with FEI's Tecnai TF20 and Titan3 80-300 TEMs, while APT was performed in a LEAP 3000X HR. DFT calculations were performed with Vienna Ab-inito Simulation Package (VASP) using the projector augmented wave method within the generalized gradient approximation of Perdew, Burke and Ernzerhof ${ }^{45,46}$. MedeA software was used for generating $\mathrm{Zn}$-substituted precipitate structures, calculation of elastic constants, and computing/analyzing charge density distributions ${ }^{47}$. All calculations were carried out with a cutoff voltage of $350 \mathrm{eV}$ and dense k-point sampling to ensure numerical accuracy. Additional details are presented in the Supplementary Methods Section.

Data availability. All data are available from the authors.

Received: 23 January 2017 Accepted: 7 November 2017

Published online: 08 December 2017

\section{References}

1. Nabarro, F. R. N. Creep in commercially pure metals. Acta Mater. 54, 263-295 (2006).

2. Kassner, M. E. \& Perez-Prado, M. T. Five-power-law creep in single phase metals and alloys. Prog. Mater. Sci. 45, 1-102 (2000).

3. Mainprice, D., Tommasi, A., Couvy, H., Colder, P. \& Frost, D. J. Pressure sensitivity of olivine slip systems and seismic anisotropy of Earth's upper mantle. Nature 4333, 731-733 (2005).

4. Miyazaki, T., Sueyoshi, K. \& Hiraga, T. Olivine crystals align during diffusion creep of Earth's upper mantle. Nature 502, 321 (2013).

5. Pollock, T. M. Weight loss with magnesium alloys. Science 328, 986-960 (2013).

6. Dehm, G. \& Bamberger, M. Trends in the development of new Mg alloys. Annu. Rev. Mater. Res. 38, 505-533 (2008).

7. Vagarli, S. S. \& Langdon, T. G. Deformation mechanism in H.C.P. metals at elevated temperatures - I. Creep behavior of magnesium. Acta Metall. 29, 1969-1982 (1981).

8. Vagarli, S. S. \& Langdon, T. G. Deformation mechanism in H.C.P. metals at elevated temperatures - I. Creep behavior of $\mathrm{Mg}-0.8 \% \mathrm{Al}$ solid solution alloy. Acta Metall. 30, 1157-1170 (1982).

9. Luo, A. \& Pekguleryuz, M. O. Cast magnesium alloys for elevated temperature applications. J. Mater. Sci. 29, 5259-5271 (1994).

10. Mordike, B. L. Creep-resistant magnesium alloys. Mater. Sci. Eng. A A324, 103-112 (2002).

11. Pekguleryuz, M. O. \& Kaya, A. A. Creep resistant magnesium alloys for powertrain applications. Adv. Eng. Mater. 5, 866-878 (2003)

12. Zhu, S. M., Nie, J. F., Gibson, M. A., Easton, M. A. \& Bakke, P. Microstructure and creep behavior of high-pressure die-cast magnesium alloy AE44. Metall. Mater. Trans. A 43, 4137-4144 (2012).

13. Athul, K. R., Pillai, U. T. S., Srinivasan, A. \& Pai, B. C. A review of different creep mechanisms in $\mathrm{Mg}$ alloys based on stress exponent and activation energy. Adv. Eng. Mater. 18, 770-794 (2016).

14. Dieter, G. E. Mechanical Metallurgy, Vol. 3 (McGraw-Hill, New York, 1986)

15. Tanelke, M., Abe, F. \& Sawada, K. Creep-strengthening of steel at high temperatures using nano-sized carbonitride dispersoids. Nature 424, 294-296 (2003).

16. Ardell, A. J. Precipitation hardening. Metall. Trans. A 16A, 2131-2165 (1985).

17. Chen, J. H., Costan, E., van Huis, M. A., Xu, Q. \& Zandbergen, H. W. Atomic pillar-based nanoprecipitates strengthened AlMgSi alloys. Science 312, 416-419 (2006).

18. Nie, J. F. Precipitation and hardening in magnesium alloys. Metall. Trans. A 43A, 3891-3939 (1985).

19. Zhu, S. M., Gibson, M. A., Easton, M. A. \& Nie, J. F. The relationship between microstructure and creep resistance in die-cast magnesium-rare earth alloys. Scr. Mater. 63, 698-703 (2010).

20. Choudhuri, D., Jaeger, D., Gibson, M. A. \& Banerjee, R. Role of $\mathrm{Zn}$ in enhancing the creep resistance of Mg-RE alloys. Scr. Mater. 86, 32-35 (2014).
21. Nie, J. F., Xiang Gao \& Zhu, S. M. Enhanced age hardening response and creep resistance of Mg-Gd alloys containing Zn. Scr. Mater. 53, 1049-1053 (2005).

22. Nie, J. F., Oh-Ishi, K., Xiang Gao \& Hono, K. Solute segregation and precipitation in a creep-resistant Mg-Gd-Zn alloy. Acta Mater. 56, 6061-6076 (2008).

23. Nie, J. F., Zhu, Y. M., Liu, J. Z. \& Fang, X. Y. Periodic segregation of solute atoms in fully coherent twin boundaries. Science 340, 957-960 (2013).

24. Easton, M. A., Gibson, M. A., Zhu, S. \& Abbott, T. B. An a priori hot-tearing indicator applied to die-cast magnesium-rare earth alloys. Metall. Mater. Trans. A 45, 3586-3595 (2014).

25. Chia, T. L. et al. The effect of alloy composition on the microstructure and tensile properties of binary $\mathrm{Mg}$-rare earth alloys. Intermetallics 17, 481-490 (2009).

26. Sutton, A. P. Electronic Structure of Materials (Clarendon Press, New York, 1993).

27. Ogata, S., Li, J. \& Yip, S. Ideal pure shear strength of aluminum and copper. Science 298, 807-811 (2002).

28. Jiang, C. \& Srinivasan, S. G. Unexpected strain-stiffening in crystalline solids. Nature 496, 339-342 (2013).

29. Issa, A., Saal, J. E. \& Wolverton, C. Physical factors controlling the observed high-strength precipitate morphology in Mg-rare earth alloys. Acta Mater. 65, 240-250 (2014)

30. Cerezo, A. \& Davin, L. Aspects of the observation of clusters in the 3dimensional atom probe. Surf. Interface Anal. 39, 184-188 (2007).

31. Hyde, J. M., Marquis, E. A., Wilford, K. B. \& Williams, T. J. A sensitivity analysis of the maximum separation method for characterization of solute clusters. Ultramicroscopy 111, 440-447 (2011).

32. Issa, A., Saal, J. E. \& Wolverton, C. Formation of high-strength $\beta^{\prime}$ precipitates in $\mathrm{Mg}-\mathrm{RE}$ alloys: the role of the $\mathrm{Mg} / \beta$ " precipitate instability. Acta Mater. 83, 75-83 (2015)

33. Nie, J. F., Wilson, N. C., Zhu, Y. M. \& Xu, Z. Solute clusters and GP zones in binary Mg-RE alloys. Acta Mater. 106, 260-271 (2016).

34. Nellist, P. D. et al. Direct sub-angstrom imaging of a crystal lattice. Science $\mathbf{3 0 5}$, 1741 (2004).

35. MacArthur, E. H. et al. Probe integrated scattering cross sections in the analysis of atomic resolution HAADF-STEM images. Ultramicroscopy 133, 109-119 (2013).

36. Choudhuri, D., Dendge, N., Nag, S., Gibson, M. A. \& Banerjee, R. Role of applied uniaxial stress during creep testing on precipitation in $\mathrm{Mg}-\mathrm{Nd}$ alloys. Mater. Sci. Eng. A 612, 140-152 (2014)

37. Hull, D. \& Bacon, D. J. Introduction to Dislocations 4th edn (ButterworthHeinmann, USA, 2001)

38. Huang, J. C. \& Ardell, A. J. Strengthening mechanisms associated with T1 particles in two Al-Li-Cu alloys. Le. J. Phys. Colloq. 48, C3-373 (1987).

39. Shewmon, P. Diffusion in Solids 2nd edn, (The Minerals, Metals \& Materials Society, USA, 1989).

40. Henkelman, G., Uberuaga, B. P. \& Jonsson, H. A climbing image nudged elastic band method for finding saddle points and minimum energy paths. J. Chem. Phys. 113, 9901 (2000).

41. Ismer, L., Park, M. S., Janotti, A. \& Van de Walle, C. G. Interactions between hydrogen impurities and vacancies in $\mathrm{Mg}$ and $\mathrm{Al}$ : a comparative analysis based on density functional theory. Phys. Rev. B 80, 184110 (2009).

42. Choudhuri, D., Banerjee, R. \& Srinivasan, S. G. Interfacial structures and energetics of the strengthening precipitate phase in creep-resistant Mg-Ndbased alloys. Sci. Rep. 7, 40540 (2017).

43. Shang, S. L. et al. Generalized stacking fault energy, ideal strength and twinnability of dilute Mg-based alloys: a first-principles study of shear deformation. Acta Mater. 67, 168-180 (2014).

44. Salloom, R., Banerjee, R. \& Srinivasan, S. G, Effect of $\beta$-stabilizer elements on stacking faults energies and ductility of $\alpha$-titanium using first-principles calculations. J. Appl. Phys. 120, 175105 (2016).

45. Kresse, G. \& Furthmuller, J. Efficiency of ab-initio total energy calculations for metals and semiconductors using plane-wave basis set, Comp. Mater. Sci. 6 , 15-50 (1996).

46. Perdew, J. P., Burke, K. \& Ernzerhof, M. Generalized gradient approximation made simple. Phy. Rev. Lett. 77, 3865-3868 (1996).

47. MedeA Atomistic Simulation Environment v.2.21 Available at http://www. materialsdesign.com/software

\section{Acknowledgements}

The computations were done on UNT's Talon3 and Texas Advanced Computing Center's Stampede supercomputer. The authors used the Materials Research Facility at UNT. D.C., R.B., and S.G.S. acknowledge support from NSF grant CMMI-1435611, and H.L.F. and Y.Z. were supported by NSF grant CMMI-1435483. Dr. T. Alam helped us with atom probe experiments. 


\section{Author contributions}

D.C., S.G.S., M.A.G., H.L.F., and R.B. contributed in designing the experiments. M.A.G. prepared the alloys used in this study and performed the creep experiments. D.C. and S. G.S. designed and executed the simulations. D.C., S.G.S., M.A.G., and R.B. wrote the manuscript with inputs/discussion with other authors. D.C. performed conventional TEM examinations and analysis of the results. Y.Z. recorded HAADF-STEM images and D.L.J. acquired and analyzed atom probe data.

\section{Additional information}

Supplementary Information accompanies this paper at https://doi.org/10.1038/s41467017-02112-z.

Competing interests: The authors declare no competing financial interests.

Reprints and permission information is available online at http://npg.nature.com/ reprintsandpermissions/

Publisher's note: Springer Nature remains neutral with regard to jurisdictional claims in published maps and institutional affiliations. (c) (i) Open Access This article is licensed under a Creative Commons Attribution 4.0 International License, which permits use, sharing, adaptation, distribution and reproduction in any medium or format, as long as you give appropriate credit to the original author(s) and the source, provide a link to the Creative Commons license, and indicate if changes were made. The images or other third party material in this article are included in the article's Creative Commons license, unless indicated otherwise in a credit line to the material. If material is not included in the article's Creative Commons license and your intended use is not permitted by statutory regulation or exceeds the permitted use, you will need to obtain permission directly from the copyright holder. To view a copy of this license, visit http://creativecommons.org/ licenses/by/4.0/.

(C) The Author(s) 2017 